\title{
Ecology of parasite Sycophilomorpha sp. on Ficus altissima and its effect on the fig-fig wasp mutualism
}

\author{
Y. Q. PENG ${ }^{1}$, J. B. ZHAO ${ }^{1,2}$, R. D. HARRISON ${ }^{1}$ and D. R. YANG ${ }^{1}$ * \\ ${ }^{1}$ Key Laboratory of Tropical Forest Ecology, Xishuangbanna Tropical Botanical Garden, Chinese Academy of Sciences, \\ Kunming, China \\ ${ }^{2}$ Graduate School of the Chinese Academy of Science, Beijing, China
}

(Received 21 Fanuary 2010; revised 12 March 2010; accepted 6 April 2010)

SUMMARY

Figs and their pollinating wasps are a classic example of an obligate mutualism. In addition, figs are parasitized by a suite of non-mutualistic wasps whose basic ecology is largely undescribed. Sycophilomorpha (subfamily Epichrysomallinae) fig wasps are ovule gallers and the genus contains only 1 described species. An undescribed Sycophilomorpha species parasitized Ficus altissima at Xishuangbana, Southwestern China. The wasp was observed ovipositing on the tiny immature figs that were still concealed beneath the involucral bracts. A Sycophilomorpha wasp oviposited on more than 1 fig and spent long time-periods to lay large clutches on a single fig. The wasps naturally occurred on all 7 sampled trees, but the occurrence of wasps was significantly different among trees, crops and months. These wasps were able to prevent unpollinated figs from being aborted, and their offspring were able to develop in the figs that otherwise had no pollinator wasps or seeds. The Sycophilomorpha wasp had a detrimental effect on the fig-fig wasp mutualism. Figs in which Sycophilomorpha wasps were present, produced significantly fewer seeds, pollinators and cheaters. However, the abundance of Sycophilomorpha in a fig was only significantly negatively correlated with pollinator production and not seed or cheater production. Our study illustrates a previously unknown fig wasp niche and expands our understanding of factors that can affect the fig-fig wasp interaction.

Key words: parasitism, coevolution, galler, mutualisim, syconia.

\section{INTRODUCTION}

Parasites typically depend upon their hosts for shelter, nutrition, and reproduction. Parasites can acquire these needs by 2 alternative strategies: exploitation and cooperation. Parasites exploit hosts to advance their own reproduction at the cost of host fitness. In contrast, mutualists increase their reproductive output by increasing host fitness (Herre, 1995; McBride et al. 2008). Parasites reduce host fitness and so can also affect that of a host's mutualists (Compton et al. 1994; Kerdelhué et al. 2000).

A majority of the 750 Ficus species (Moraceae, see Berg, 1989) is involved in a species-specific obligate mutualism with its pollinator chalcid wasp (Hymenoptera: Agaonidae), which also strictly depends on its host fig for reproduction. The system forms a remarkable plant-insect obligate mutualism (Ramirez, 1970; Galil, 1977; Wiebes, 1979). Figs also support a diverse community of non-mutualistic wasps (Compton et al. 1994; Kerdelhué et al. 2000). Both morphological and molecular data suggest an ancient association between these wasps and their hosts.

* Corresponding author: Key Laboratory of Tropical Forest Ecology, Xishuangbanna Tropical Botanical Garden, Chinese Academy of Sciences, Kunming, 650223, China. Tel: + 8608715127180 . Fax: + 860871 5160916. E-mail: yangdr@xtbg.ac.cn
Despite providing no pollinating services, and so having no apparent benefit to the fig, these nonmutualistic wasps are ubiquitous (West and Herre, 1994; Kerdelhué and Rasplus, 1996; Jousselin et al. 2006; Marussich and Machado, 2007). These wasps include gallers, inquilines, kleptoparasites, parasitoids of the pollinators, and parasitoids of other nonpollinating wasp species (Kerdelhué et al. 2000; Peng et al. 2005a,b). Up to 32 species have been described in association with a single fig species (Bronstein, 1999). In every study that has examined the relationships in detail, non-pollinating fig wasps have been found to have a negative impact on pollinator production, and sometimes also on seed production (Compton et al. 1994; West and Herre, 1994; West et al. 1996).

Non-pollinating fig wasps belonging to different families and subfamilies have in some cases exhibited ecological convergence in fig utilization (van Noort and Compton, 1996; Rasplus et al. 1998). Each particular species oviposits at a specific stage of fig maturation (Elias et al. 2008). However, regardless of the time when they oviposit in the fig flowers, all fig wasp species will emerge from the galls in the fig cavity at the same time as the pollinator (Kerdelhué et al. 2000; Peng et al. 2005a). Among nonpollinating fig wasps, all the species of subfamily Epichrysomallinae are gall-makers. They oviposit in 
very young syconia prior to pollinator arrival, and induce very large galls that protrude in the fig cavity (Kerdelhué et al. 2000; Niu et al. 2009). They usually gall the flowers (Galil and Copland, 1981), but also apparently the fig wall (J. Y. Rasplus, unpublished data) or on twigs (Ferrière, 1929). In Africa, the subfamily Epichrysomallinae is well represented with nearly 40 species. It is also distributed in the IndoAustralasian region, but most species are undescribed (Boucek, 1988). Unlike the pollinators, epichrysomallinae wasps attack the flowers by piercing the outside of the receptacle. During oviposition, epichrysomalline females inject the contents of their acid gland reservoirs in the ovaries, which stimulates parthenogenetic nucellar development to provide food for the offspring (Galil and Copland, 1981).

Sycophilomorpha genus belonging to subfamily Epichrysomallinae is distributed in the Asian continent, and only 1 species (Sycophilomorpha saptapurensis Joseph and Abdurahiman, 1969) has been described. The fig host is Ficus bengalensis in India (Joseph and Abdurahiman, 1969). Nothing about the biology and ecology of this genus has been reported. Sycophilomorpha sp. was found to parasitize $F$. altissima at Xishuangbanna, South-western China. Both $F$. bengalensis and $F$. altissima belong to Subgenus Urostigma and Section Conosycea, and their pollinators are Eupristina wasps (Priyadarsanan, 2000). However, F. altissima presents an interesting case for studying factors affecting the stability of the fig-fig pollinator interaction, because of the presence of a cheater - a species congeneric with the pollinator that does not pollinate (Peng et al. 2008). Hence, in this study we observed the ecology of Sycophilomorpha sp. and investigated its effect on this tripartite interaction.

\section{MATERIALS AND METHODS}

\section{Study site}

The study was carried out around Menglun town, Xishuangbanna in tropical Southwest China $\left(21^{\circ} 55^{\prime} \mathrm{N}, 101^{\circ} 15^{\prime} \mathrm{E}\right.$, at about $555 \mathrm{~m}$ asl). Temperature and rainfall data collected for 40 years at Xishuangbanna Forest Ecology Station, less than $3 \mathrm{~km}$ from the research area, show that annual temperature averages $21.8^{\circ} \mathrm{C}$, with means of $25.7{ }^{\circ} \mathrm{C}$ in the hottest month (June) and $16.0^{\circ} \mathrm{C}$ in the coldest month (January). Average annual relative humidity is $85.0 \%$ and rainfall is variable, with distinct rainy (May-October) and dry (NovemberApril) seasons.

\section{Study species}

Ficus altissima (Subgenus Urostigma, Section Conosycea: Berg and Corner, 2005) is distributed across Asia (Corner, 1965). At Xishuangbanna, the species occurs naturally in tropical forest, but is frequently planted in cities, villages or near temples both as an ornamental and as a sacred plant. The twigs renew leaf and initiate syconia simultaneously. Figs are produced in synchronous crops with asynchrony between trees. At the time they release their fig wasps they are yellow and average $14.0 \mathrm{~mm}$ in diameter (s.E. $=0.99 n=679)$. Large crops can number many thousands of figs. Ficus altissima is actively pollinated by the agaonid Euptistina altissima, but also supports an undescribed congener (Eupristina $\mathrm{sp}$.) that has reduced pollen pockets and there is no coxal comb. This species has evolved into a cheater that fails to pollinate, it represents 1 of only 2 known cases in which a fig species harbours a species congeneric with the pollinator that has ceased to pollinate (Peng et al. 2008). In addition to the 2 agaonids, $F$. altissima also locally supports at least 25 further species of non-pollinating fig wasps (NPFW) belonging to families other than the Agaonidae ( $\mathrm{Gu}$ et al. 2003). Their detailed biology is largely unknown, but they include ovule gallers and parasitoids. Sycophilomorph sp. is an ovule galler and oviposits prior to pollinator arrival. Males are winged and mating occurs outside of the fig. The mean body size of the Sycophilomorph wasp is $1.96 \pm 0.02(n=7)$ and it is larger than the pollinator (mean $1.85 \pm 0.01 \mathrm{~mm}$, $n=96)$.

\section{Observation of oviposition behaviour}

The twigs renewed leaf and initiate syconia simultaneously in F. altissima, and Sycophilomorph sp. is an early ovipositing species. So, once new leaves appeared, the development of the syconia was tracked. When Sycophilomorph sp. was found to oviposit, we took photographs using a Nikon 995 camera to record the oviposition site and posture of the wasp, and opened the fig to record the developmental status of female flowers using a camera installed in a microscope (Olympus SZX12). The figs with Sycophilomorph sp. eggs were tracked on the twigs until the pollinator entry. Figs were also opened to check the galls in the post-pollination phase.

\section{Collection of Sycophilomorpha sp. in natural fig}

Seven $F$. altissima trees were selected to collect figs at the male (wasp releasing) stage. The sampled trees were checked weekly from 13 January 2003 to 6 December 2005 . When present, 30 nearly mature D-phase figs that were producing wasps per crop were collected. Each fig was placed individually in a fine-mesh bag $(20 \times 20 \mathrm{~cm})$, and the fig wasps were allowed to emerge. All fig wasps, including those remaining inside the figs, were carefully collected and preserved in $70 \%$ ethanol. The sexes of Sycophilomorpha sp. were identified and their numbers 


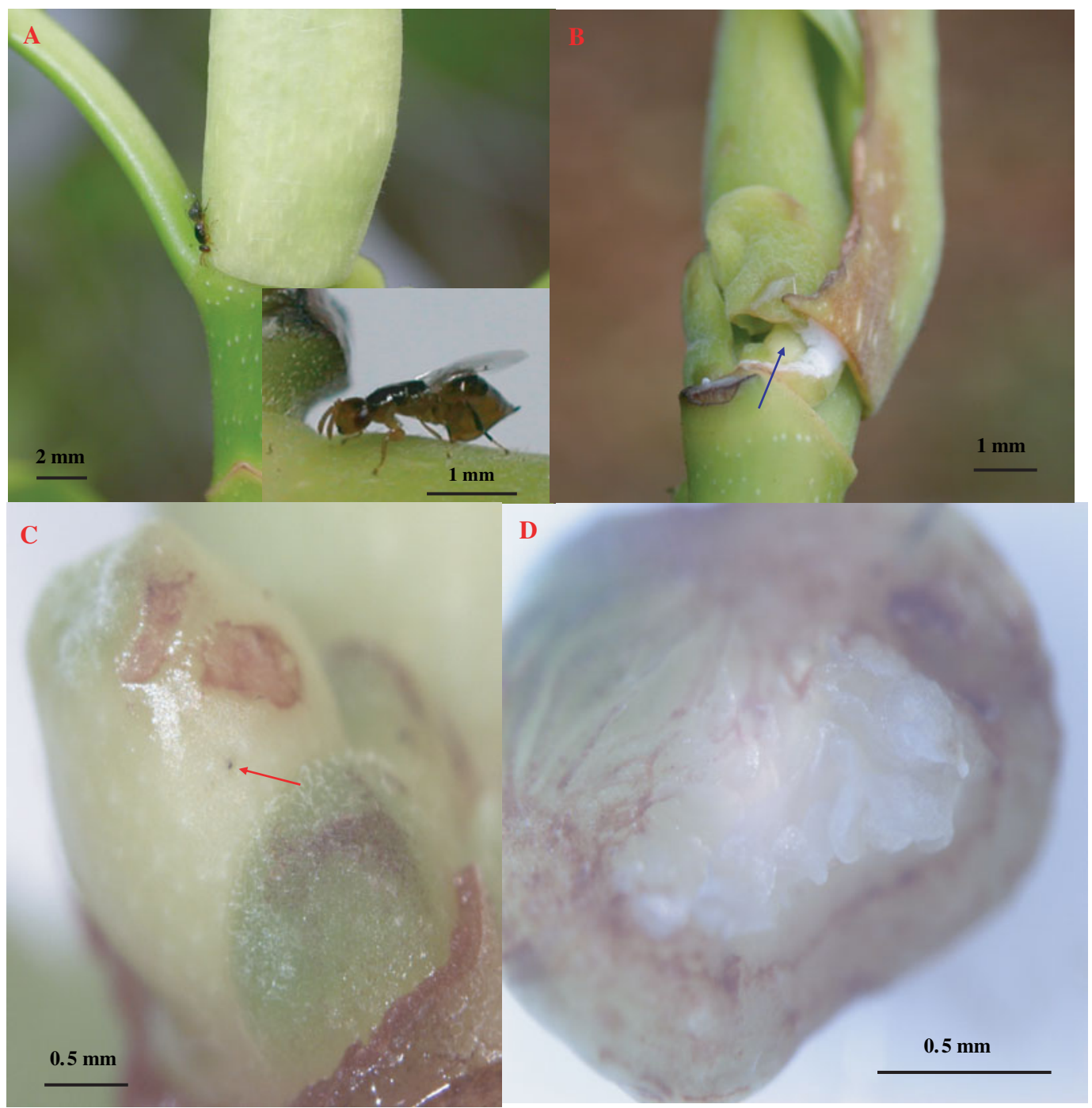

Fig. 1. Oviposition behaviour of Sycophilomorpha sp. (A) When Sycophilomorpha sp. was ovipositing the fig was still covered by hood-like involucral bracts and the stipule. (B) The blue arrow indicates the position of the hidden fig. (C) The ovipositor pierced the fig wall and left a small black scar (red arrow). (D) The flowers in such young figs had not yet differentiated into ovule, style, and stigma.

were counted. During the 3 years, a total of 679 figs were collected from 23 crops.

\section{Statistical analyses}

We used binomial models to examine variation in the occurrence of Sycophilomorpha sp. among trees, crops (nested within trees) and months. We also used binomial models to examine the effect of Sycophilomorpha sp. on the occurrence of pollinators, seeds and cheaters. Next, to examine the effect of the presence of Sycophilomorpha sp. on the contents of a fig, we used t-tests to compare fig diameter, the number of female flowers, male flowers, pollinators, seeds and cheaters between figs with and without Sycophilomorpha sp. In the latter tests we selected only those figs that had pollinators, seeds and cheaters, respectively. Finally, we used general linear models, with a negative binomial distribution of the error term, to examine the effect of the number of Sycophilomorpha sp. present on the numbers of pollinators, seeds and cheaters, using only those figs that had Sycophilomorpha sp. and pollinators, seeds and cheaters, respectively. We elected to analyse occurrence and quantitative effects separately because of the large number of zero values (absences) in our dataset. All analyses were performed in R v2.9.2 program.

\section{RESULTS}

Oviposition behaviour of Sycophilomorpha $s p$. in Ficus altissima

Sycophilomorpha sp. oviposited very early, when the new twigs appeared and the new leaves were still covered by their stipules (Fig. 1A). At this stage the new figs were covered by hood-like involucral bracts (Fig. 1B), and only approximately $1.43 \mathrm{~mm}$ in 


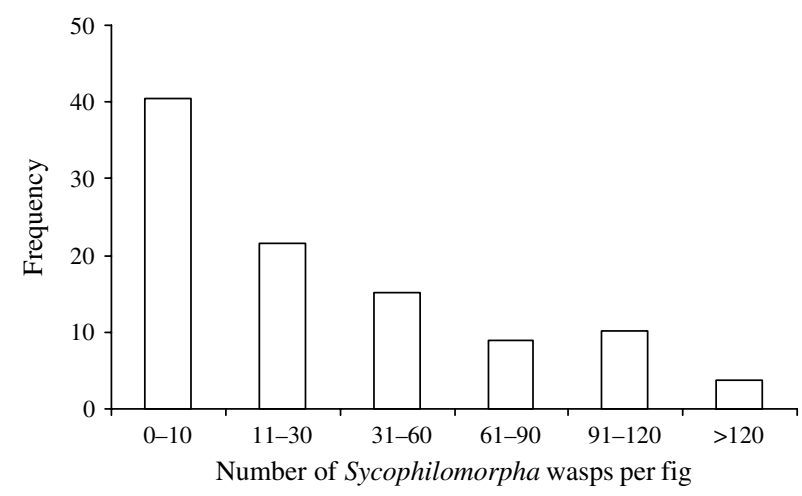

Fig. 2. A frequency distribution of the number of Sycophilomorpha wasps per sampled fig.

diameter. This is the only reported case of fig wasps ovipositing so early in the development of the syconia. Sycophilomorph sp. oviposited for several hours to 1 day on the same fig. When Sycophilomorph sp. finished ovipositing and left, a small black spot representing the scar left by the ovipositor could be seen on the fig under the microscope (Fig. 1C). Sycophilomorph sp. moved among a small number of figs to oviposit. When oviposited figs were opened, there was no discernible structure to the female flowers (i.e. ovary, style, stigma, pedicel and petal) under the microscope (Fig. 1D). The development of the figs with and without Sycophilomorph wasps was very long. For example, on 21 September 2009 Sycophilomorpha sp. was observed ovipositing on one tree but the pollinators did not enter the figs on the same tree until 10 January 2010 or over 3 months later. Figs with and without Sycophilomorpha sp. developed in synchrony. The galls made by Sycophilomorph had long pedicels and protruded into the fig cavity, but the gall flower had no style or stigma.

Occurrence of Sycophilomorpha sp. in Ficus altissima

In total, $11 \cdot 5 \%$ of figs were colonized by Sycophilomorpha sp. in F. altissima in Xishuangbanna, and varied from 0 to $50 \%$ among 23 crops. A single gall housed 1 Sycophilomorpha wasp. On average, the number of Sycophilomorpha wasps per occupied fig was $35 \cdot 13 \pm 4 \cdot 58$ (s.E., $n=79$ ), the range was 1 to 172 . By comparison, the average number of agaonid wasps per fig was $163 \cdot 15 \pm 5 \cdot 11$ (s.E., $n=312$ ). About $40 \%$ of figs colonized produced less than 10 Sycophilamorpha sp. offspring, $45 \%$ of the figs produced $10-90$ offspring, and $15 \%$ of the figs produced more than 90 offspring per fig (Fig. 2). Sycophilomorpha sp. naturally occurred in all 7 sampled trees, but the occurrence of wasps was significantly different among trees $(z=3 \cdot 487, P=0.00049)$ and crops $(z=4 \cdot 628$, $P<0 \cdot 00001)$. The effect of month on the occurrence of Sycophilomorpha was also significant but was relatively weak $(z=-2 \cdot 079, \quad P<0 \cdot 05)$.
Sycophilomorpha sp. were observed from March to August and the proportion of figs occupied was higher in 2004 (Fig. 3).

\section{The effect of Sycophilomorpha sp. on the fig-fig wasp interaction}

Figs with Sycophilomorpha sp. were small (mean diameter $=11 \cdot 19 \pm 0 \cdot 23, n=50)$, and had significantly fewer female flowers $(\mathrm{t}=-6 \cdot 92$, D.F. $=91 \cdot 24, \quad P<$ $0 \cdot 00001$; mean $=391 \cdot 14)$ than figs without Sycophilomorpha sp. (mean diameter $=12 \cdot 38 \pm 0 \cdot 20$, mean number of flowers $=520 \cdot 55$ ) (Fig. 4). Therefore, colonization by Sycophilomorpha sp. reduced fig size and the flower resources available for oviposition.

Sycophilomorpha sp. had a highly significant negative effect on the occurrence of pollinators $(\mathrm{z}=-8 \cdot 408, P<0 \cdot 00001)$ and seeds $(\mathrm{z}=-7 \cdot 170, P<$ $0 \cdot 00001)$ after controlling for the effect of cheaters, and on cheaters $(z=-8.588, P<0 \cdot 00001)$ after controlling for the effect of pollinators. Thus, figs colonized by Sycophilomorpha sp. were less likely to be entered by either a pollinator or cheater.

Figs with Sycophilomorpha sp. had significantly fewer pollinators $(\mathrm{t}=-3 \cdot 15$, D.F. $=15 \cdot 66, P=0 \cdot 0061$, mean with $=72 \cdot 53$, mean without $=138 \cdot 07)$, seeds $(\mathrm{t}=-2 \cdot 73$, D.F. $=28 \cdot 61, P=0 \cdot 011$, mean with $=84 \cdot 23$, mean without $=141 \cdot 03)$, and cheaters $(t=-5.93$. D.F. $=29 \cdot 90, P<0 \cdot 00001$, mean with $=26 \cdot 83$, mean without $=79 \cdot 07)($ Fig. 4).

However, in figs with both Sycophilomorpha sp. and pollinators, seeds and cheaters, respectively, Sycophilomorpha sp. had a significant effect on the numbers of pollinators $(z=-2 \cdot 54, P=0.0119)$ but not seeds $(z=0.862, P=0.409)$ or cheaters $(z=-1 \cdot 664, P=0 \cdot 0962)$. Thus, while the presence or absence of Sycophilomorpha sp. had a significant effect on seed and cheater production, the abundance of Sycophilomorpha did not.

In summary, Sycophilomorpha sp. had a substantial detrimental effect on the reproductive success of F. altissima and its pollinator. Sycophilomorpha sp. occupied $11 \cdot 5 \%$ of figs. Of these, $64 \%$ were not entered by a pollinator or cheater and Sycophilomorpha sp. was able to prevent these unpollinated fruit from being aborted. In the remaining figs colonized by Sycophilamorpha sp. and pollinators or cheaters the production of pollinators, seeds, and cheaters were all approximately half the normal levels. However, in these figs the abundance of Sycophilomorpha sp. only had a significant effect on the abundance of pollinators.

\section{DISCUSSION}

Sycophilomorpha wasps oviposited earlier in fig development than is reported for any other nonpollinating fig wasps (Weiblen, 2002). At this stage, 


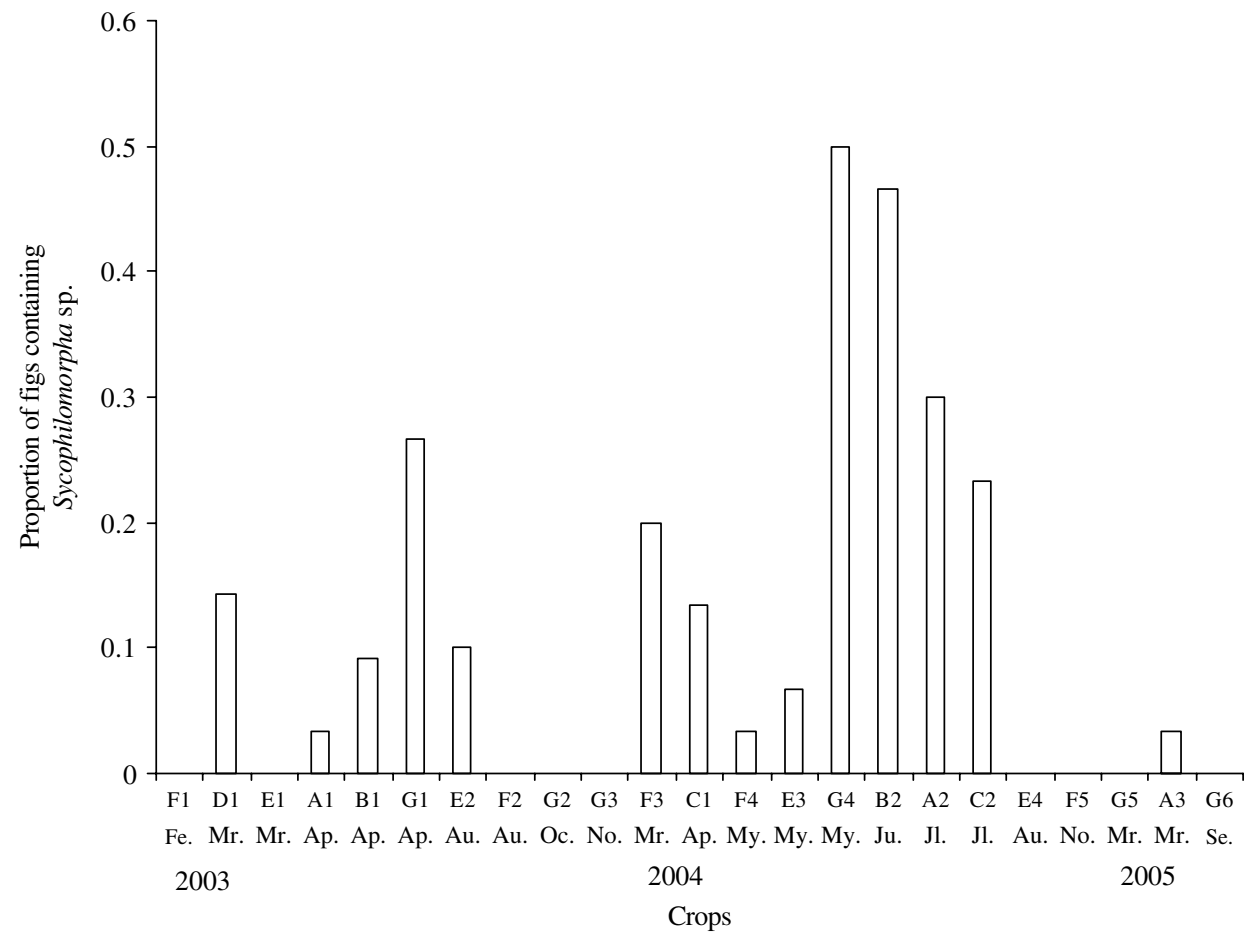

Fig. 3. Occurrence of Sycophilomorpha sp. among sampled crops (arranged chronologically). The uppercase letters represent the different trees and the number the sequential crop number on a particular tree.
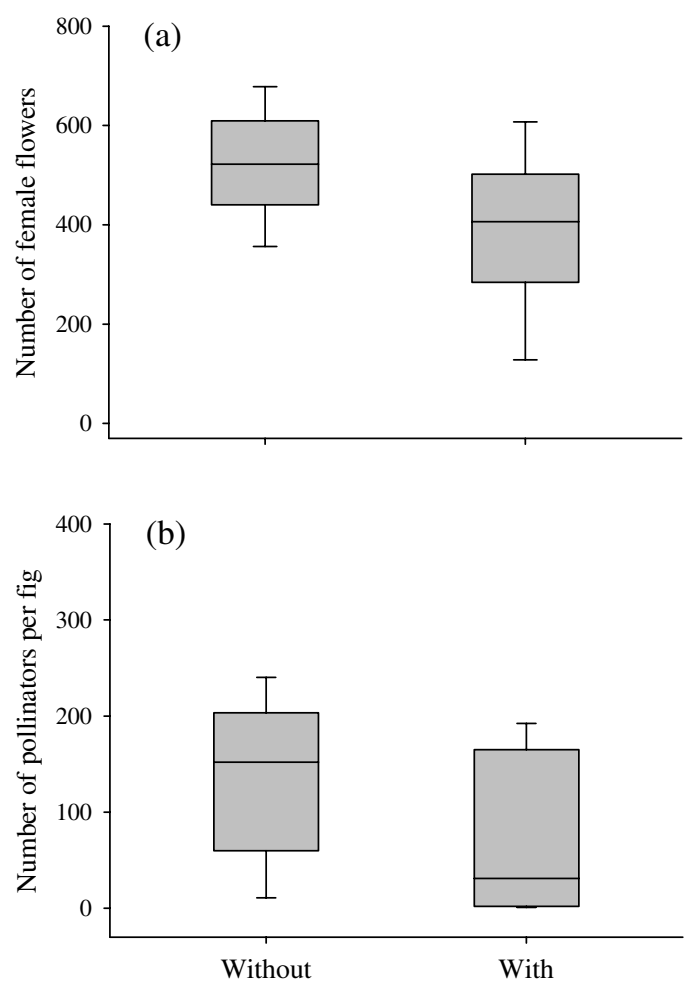
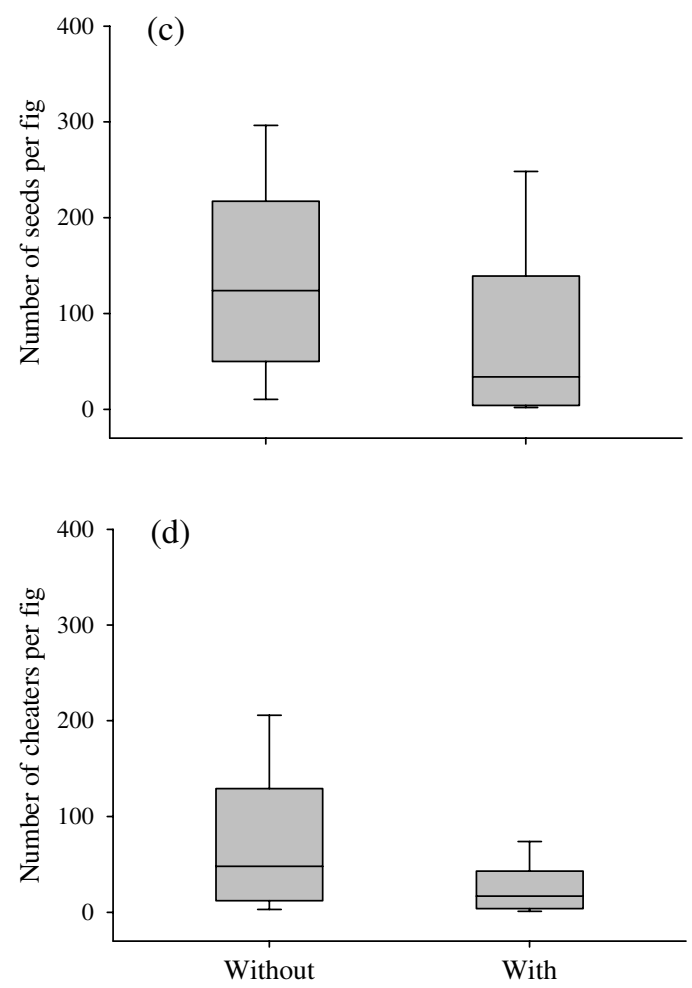

Fig. 4. Comparison of fig contents with and without Sycophilomorpha sp. (without, $n=600$; with, $n=79$ ). (a) number of flowers, (b) the number of pollinators, (c) the number of seeds, and (d) the number of cheaters. The numbers of flowers, pollinators, seeds and cheaters were all significantly reduced in figs with Sycophilomorpha sp. (see text for details).

there was no discernible structure to the female flowers. This study also found that the immature phase of fig development is longer than previously reported. Sycophilomorpha wasps also influenced flower development preventing any differentiation into style and stigma. 
Most of the non-pollinating fig wasps are rare and rarely abundant in any given fig (Weiblen and Bush, 2002). Similarly, Sycophilomorpha sp. only occurred in 8 out of 23 crops and overall colonized $11 \cdot 5 \%$ of sampled figs. However, Sycophilomorpha sp. sometimes laid large clutches in a single fig. More than $50 \%$ of the figs colonized by Sycophilomorpha produced more than 10 offspring, and occasionally over 100 offspring. In the figs with Sycophilomorpha sp., $64 \%$ of the figs only produced Sycophilomorpha offspring. This indicates that different non-pollinating wasp genera employ different reproductive strategies, despite having an apparently similar ecology in other respects.

Sycophilomorpha sp. naturally occurred in every tree, but the occurrence of wasps varied significantly among trees, crops and months. Over the 2 years of observation Sycophilomorpha sp. occurred from March to August. Our observations indicate that the development of Sycophilomorph wasps can be very slow, approximately 6 months from oviposition in September 2009 to emergence in March 2010. The duration of fig development in Ficus altissima varies widely depending on the season, and is longer in the winter when temperatures reach as low as $10^{\circ} \mathrm{C}$ at night than in the warm season (Peng et al. 2010). It is not clear from our relatively short observation window, whether the absence of Sycophilomorpha wasps from September to March is just a stochastic effect of their long development or a strategy to avoid the coldest part of the year.

Non-pollinating parasitoids and gallers are speciesrich components of fig wasp assemblages, and have negative impacts on the fig-fig pollinator mutualism through predation of pollinator larvae, through competition with pollinators for seed resources and through use of ovules that might otherwise become seeds (Compton et al. 1994; West and Herre, 1994; West et al. 1996). Moreover, all non-pollinating fig wasps drain energetic resources from the host plant. If gallers oviposit before the pollinator, they may directly compete with the pollinator by reducing the number of ovules available for oviposition or indirectly by inhibiting the ability of the pollinator to lay eggs. In the case of $F$. altissima, when the pollinator entered a fig that had been colonized by Sycophilomorpha sp. they may have found it difficult to oviposit, because the galls of Sycophilomorpha protrude into the fig cavity. Inhibited movement by the pollinator within the fig cavity could also have a negative impact on seed production through reduced pollen dispersal, as appears to be the case in F. altissima. Sycophilomorpha sp., colonized $11 \cdot 5 \%$ of figs, $64 \%$ of these figs did not produce any seeds or pollinators, and in those that were entered by an agaonid, figs with Sycophilomorpha sp. had significantly fewer pollinators, cheaters and seeds.

Through a differential effect on pollinators and cheaters it is possible that Sycophilomorpha sp. could affect the interaction between these competing species, possibly contributing to stable coexistence. However, in comparing the strengths of the effects of Sycophilomorpha sp. on these species, we find limited support for this. Sycophilomorpha sp. had an almost identical effect on both species in terms of the occurrence, which was the most important effect we measured. The presence of Sycophilomorpha sp. did have a stronger effect on the number of cheaters than on the number of pollinators when comparing figs with and without Sycophilomorpha sp. However, the abundance of Sycophilomorpha sp. had a significant effect on pollinator but not cheater abundance. Combined, these figures translate into a reduction in pollinator production of $1.92 \%$ and in cheaters of $2 \cdot 70 \%$. Thus, the percentage difference in the effect on pollinators and cheaters is just $0.78 \%$. Given the high mortality rates of agaonids (approximately 99\% died without reproducing), it is doubtful that such a small difference could be important.

Our study has shown that, despite their rarity, Sycophilamorpha sp. have a significant impact on the fig-fig wasp mutualism in $F$. altissima. Given the ubiquity of non-pollinating fig wasps, many of which are much more abundant than Sycophilomorpha, it is perhaps surprising that the fig-fig wasp mutualism is stable across so many species (approximately $800 \mathrm{spp}$. globally). A greater appreciation of the effects of nonpollinating wasps would enhance our understanding of the factors that have contributed to the evolutionary success of the fig-fig wasp mutualism.

\section{ACKNOWLEDGEMENTS}

We are most grateful to Jean-Yves Rasplus for identifying the fig wasp. We are also thankful to Cong Liu, and Shi-Bo Wu for field assistance. We further thank Zhu-Biao Duan, Dong-Hua Zhou, Zhi-Mei Zhou and Jin-Yuan Zhang for counting the wasps and seeds, and thank Allen Edward Herre and Steve Compton for their useful comments. This study was funded by the Chinese Natural Science Foundation (30670358, 30970439 and 30972294) and Presidential Foundation of the Chinese Academy of Sciences.

\section{REFERENCES}

Berg, C. C. (1989). Classification and distribution of Ficus. Experientia 45, 605-611.

Berg, C. C. and Corner, E. J. H. (2005). Moraceae (Ficus). In Floral Malesiana, Series I, Vol. 17(2) (ed.

Nooteboom, H. D.), pp. 1-625. National Herbarium of Nederland, Leiden, The Netherlands.

Boucek, Z. (1988). Australian Chalcidoidea (Hymenoptera). Centre for Agriculture and Biosciences International, Wallingford, pp. 1-832.

Bronstein, J. L. (1999). Natural history of Anidarnes bicolor (Hymenoptera: Agaonidae), a galler of the Florida strangling fig (Ficus aurea). Florida Entomologist 82, 454-464. 
Compton, S. G., Rasplus, J. Y. and Ware, A. B. (1994). African fig wasp parasitoid communities. In Parasitoid Community Ecology (ed. Hawkins, B. A. and Sheehan, W.), pp. 343-370. Oxford University Press, Oxford, $\mathrm{UK}$.

Corner, E. J. H. (1965). Checklist of Ficus in Asia and Australasia with keys to identification. The Gardens' Bulletin Singapore 21, 1-186.

Elias, L. G., Menezes, A. O., Jr. and Pereira, R. A. S. (2008). Colonization sequence of non-pollinating fig wasps associated with Ficus citrifolia in Brazil. Symbiosis 45, 107-111.

Ferrière, C. (1929). Chalcidiens gallicoles de Java. Annales de la Société Entomologique de France 48, 143-161.

Gali1, J. (1977). Fig biology. Endeavour 1, 52-56.

Galil, J. and Copland, J. W. (1981). Odontofroggatia galili Wiebes in Israel: a primary fig wasp of Ficus microcarpa L. with a unique ovipositor mechanism (Epichrysomallinae, Chalicidoidea). Proceedings of the Koninklijke Nederlandse Akademie van Wetenschappen (C) 84, 183-195.

Gu, H. Y., Yang, D. R., Zhang, G. M., Peng, Y. Q. and Song, Q. S. (2003). Species of fig wasps in Ficus altissima and their ecological characters. Chinese Fournal of Ecology 22, 70-73.

Herre, E. A. (1995). Factors affecting the evolution of virulence: nematode parasites of fig wasps as a case study. Parasitology 111, S179-S191.

Joseph, K. J. and Abdurahiman, U. C. (1969). Contributions to our knowledge of fig insects (Chalcidoidea: Hymenopterai from India. IV. Further descriptions of new fig insects from Ficus bengalensis L. Oriental Insects 3, 37-45.

Jousselin, E., Van Noort, S., Rasplus, J. Y. and Greeff, J. M. (2006). Patterns of diversification of Afrotropical Otiteselline fig wasps: phylogenetic study reveals a double radiation across host figs and conservatism of host association. Fournal of Evolutionary Biology 19, 253-266.

Kerdelhué, C. and Rasplus, J. Y. (1996). Nonpollinating afrotropical fig wasps affect the fig-pollinator mutualism in Ficus within the subgenus Sycomorus. Oikos 75, 3-14.

Kerdelhué, C., Rossi, J. P. and Rasplus, J. Y. (2000). Comparative community ecology studies on Old World figs and fig wasps. Ecology 81, 2832-2849.

Marussich, W. A. and Machado, C. A. (2007). Host-specificity and coevolution among pollinating and nonpollinating New World fig wasps. Molecular Ecology 16, 1925-1946.

McBride, R., Greig, D. and Travisano, M. (2008). Fungal viral mutualism moderated by ploidy. Evolution 62-9, 2372-2380.
Niu, L. M., Hu, H. Y., Huang, D. W., Fu, Y. G. and Peng, Z. Q. (2009). Brood size: a major factor influencing male dimorphism in the non-pollinating fig wasp Sycobia sp. Ecological Entomology 34, 696-701.

Peng, Y. Q., Yang, D. R. and Wang, Q. Y. (2005a). Quantitative tests of interaction between pollinating and non-pollinating fig wasps on dioecious Ficus hispida. Ecological Entomology 30, 70-77.

Peng, Y. Q., Yang, D. R. and Duan, Z. B. (2005b). The population dynamics of a non-pollinating fig wasp on Ficus auriculata at Xishuangbanna, China. Fournal of Tropical Ecology 21, 581-584.

Peng, Y. Q., Duan, Z. B., Yang, D. R. and Rasplus, J. Y. (2008). Co-occurrence of two Eupristina species on Ficus altissima in Xishuangbanna, Southwestern China. Symbiosis 45, 9-14.

Peng, Y. Q., Compton, S. G. and Yang, D. R. (2010). The reproductive success of Ficus altissima and its pollinator in a strongly seasonal environment: Xishuangbanna, Southwestern China. Plant Ecology doi:10.1007/s11258-009-9690-4.

Priyadarsanan, D. R. (2000). Fig insects of Kerala. In Records of the Zoological Survey of India, pp. 1-175. The publication Division by the Director, Zoological Survey of India, India.

Ramirez, B. W. (1970). Host specificity of fig wasps (Agaonidae). Evolution 24, 680-691.

Rasplus, J. Y., Kerdelhué, C., Clainche, I. L. and Mondor, G. (1998). Molecular phylogeny of fig wasps (Hym. Chalcidoidea): Agaonidae are not monophyletic. Comptes-Rendus de l'Académie des Sciences (Paris), Série III 321, 517-527.

Van Noort, S. and Compton, S. G. (1996). Convergent evolution of agaonine and sycoecine (Agaonidae, Chalcidoidea) head shape in response to the constraints of host fig morphology. Fournal of Biogeography 23, 415-424.

Weiblen, G. and Bush, G. (2002). Speciation in fig pollinators and parasites. Molecular Ecology 11, 1573-1578.

Weiblen, G. D. (2002). How to be a fig wasp. Annual Review of Entomology 47, 299-330.

West, S. A. and Herre, E. A. (1994). The ecology of the New World fig-parasitizing wasps Idarnes and implications for the evolution of the fig-pollinator mutualism. Proceedings of the Royal Society of London, $B$ 258, 67-72.

West, S. A., Herre, E. H., Windsor, D. M. and Green, R. S. (1996). The ecology and evolution of the New World nonpollinating fig wasp communities. Fournal of Biogeography 23, 447-458.

Wiebes, J. T. (1979). Co-evolution of figs and their insect pollinators. Annual Review of Ecology and Systematics 10, $1-12$. 